\title{
O processo de construção da coerência em textos narrativos na escola
}

Flávia Isaia Pinbeiro*

Resumo: O presente artigo tem por objetivo discutir o conceito de texto e os tipos de narrativas escolares infantis à luz das obras de Piaget referentes ao terceiro período (fim dos anos 30 ao fim dos anos 50), bem como apresentar alguns dados iniciais referentes ao estudo de doutorado da professora pesquisadora, realizado com sujeitos pré-adolescentes que frequentavam, no ano de 2008 , o $5^{\circ}$ ano de escolaridade, em escola pública da Rede Municipal de Ensino, em Porto Alegre. A análise dos dados de duas meninas conduz aos seguintes pressupostos: para que ocorram avanços cognitivos no sujeito, a leitura e a interpretação exercem um papel fundamental na melhoria da capacidade de descentração e, consequentemente, na diferenciação entre o que o autor pensa, o que ele escreve e como utiliza os recursos da escrita para se fazer compreender.

Palavras-chave: Texto, Narrativas escritas, Coerência, Descentração.

\footnotetext{
Abstract: This article aims to discuss the concept of text and the types of school children's narratives according to Piaget's works of the third period (late 30s to late 50s), and present some initial data from the doctoral studies of the teacher researcher, conducted with pre-adolescent subjects who, in 2008, attended the 5 th grade in a public municipal school in Porto Alegre.

Doutoranda em Educação na Faculdade de Educação da UFRGS; Professora de Ensino Fundamental na Rede Municipal de Ensino de Porto Alegre. E-mail: fpisaia@terra.com.br
} 
Data analysis of two girls leads to the following assumptions: for advancing in the subject's cognitive abilities, reading and interpretation play a significant role in improving the capacity of decentration and hence the differentiation between what the author thinks, what he writes and how he uses the resources of writin in order to make himself understood.

Keywords: Text, Written narratives, Coherence, Decentration.

\section{Introdução}

Hoje sabemos que o trabalho com linguagem, na escola, vem se caracterizando cada vez mais pela presença do texto, quer enquanto objeto de leituras, quer enquanto trabalho de produção.

Se o texto escrito pelo aluno é para ser lido, e se a leitura é mais do que simples "informação" que se extrai do texto, mas efetivamente envolve o leitor, o professor não poderia ignorar as perguntas que as informaçóes dadas pelo texto fazem surgir. As perguntas já não são perguntas didáticas, mas perguntas efetivas que fazem do diálogo da sala de aula uma troca e a construção do texto oral coenunciado. As respostas dos alunos já não são candidatas a respostas que o professor cotejaria com uma resposta previamente formulada. A participação do professor neste diálogo já não é de aferição, mas de interlocução.

Interessa-nos aqui esta concepção de linguagem descrita como uma forma de interação, que implica uma postura educacional diferenciada justamente por situar a linguagem como sendo o lugar de constituição de relações sociais, onde os falantes se tornam sujeitos.

Ao contrário de muitos estudos que relacionam a leitura e a produção escrita a um processo sócio-histórico-cultural de desenvolvimento fundamentado na perspectiva vygotskiana, tenho investigado o meu problema de pesquisa a partir da teoria de Piaget. 
Do ponto de vista psicológico, sabemos que o essencial são as transformações e os processos que ocorrem quando o sujeito aprende. É justamente esse aspecto que interessa à minha investigação, porque para tornar eficaz o processo educativo e para explicar a formação do conhecimento, é imprescindível entender o que ocorre no interior do sujeito e este, sem dúvida, foi o grande mérito da posição de Piaget.

\section{A coerência na escrita de textos}

Nesta seção discutirei acerca do conceito de texto utilizado por Geraldi (1997) para estabelecer algumas relações com o desenvolvimento cognitivo do sujeito e, ainda, sobre a idéia da atividade com textos como sendo uma atividade de produção de sentidos.

Tomemos, então, o conceito de texto utilizado por Geraldi (1997, p. 101): "Um texto é uma seqüência verbal escrita coerente formando um todo acabado, definitivo e publicado"1.

Com relação à característica da coerência, o autor nos diz que uma mera justaposição de sequências verbais escritas não chega a constituir um texto; quando o processo de construção de um texto aparentemente se faz pela justaposição de sequências verbais sem ligações entre si, no processo de compreensão de tais textos é preciso buscar nos espaços em branco as ligações possíveis (GERALDI, 1997, p. 100). Quanto à característica do todo, Geraldi (1997, p. 100) acrescenta que "[...] só buscamos preencher espaços em branco de sequências justapostas se supomos que elas se apresentam como partes de um todo".

Podemos observar que ambas as características, coerência e todo, implicam-se mutuamente. Pensemos nelas agora sob o ponto de vista da sua organização no pensamento.

Sabemos que o percurso do pensamento na criança está intimamente relacionado com o grau de reversibilidade atingido pelo seu raciocínio. Assim, a criança poderá construir uma história

\footnotetext{
Grifo meu.
} 
fazendo uso de uma linguagem impregnada de egocentrismo e de afirmações justapostas, ligadas pelo termo $e$, ao utilizar-se de conectivo ou verbo indicando o vínculo causal e estando a meio caminho para fazer da narrativa um todo coerente (PINHEIRO, 2004 , p. 145). Nesse caso, o importante é que a escrita da criança marque uma relação, manifestando uma certa ordem entre as partes da história, além de marcar também o vínculo causal ao se referir à razão dos acontecimentos da história. As ligações temporais, causais e lógicas indicam, assim, uma aproximação, ou até mesmo a chegada, à representação conceptual de ordem operatória.

Aprendemos com Piaget, tanto em $A$ construção do real na criança (1937) como em $A$ noção de tempo na criança (1946) que a noção de tempo supõe a de espaço e que o tempo é solidário da causalidade. Desse modo, podemos pensar que o esforço que o sujeito faz para comunicar objetivamente seu pensamento por escrito envolve a capacidade de pensar sob outros pontos de vista, especialmente de pensar sob o ponto de vista do leitor de seu texto. Lembremos aqui que, segundo Geraldi (1997, p. 102), "[...] o outro passa a ser a medida: é para o outro que se produz o texto. [...] O outro insere-se já na produção, como condição necessária para que o texto exista”. Surgirá, então, a necessidade de explicar para o leitor, tanto através da voz do narrador como da voz dos personagens, as situações que ocorrem no decorrer da história de forma a descrever e relacionar os objetos, personagens e o ambiente no qual eles estão inseridos.

Ao relacionar os eventos que preenchem o tempo na história, o sujeito estabelecerá uma sequência de acontecimentos através da ordenação (antes/depois) entre os fatos que acontecem na história. Trata-se da ordem das sucessões: "[...] é o discurso narrativo, isto é, o comportamento que consiste em reconstruir a sequência dos acontecimentos quando esta sequência não pode mais ser objeto de uma percepção direta” (PIAGET, 1946, p. 285). O comportamento do discurso narrativo da criança, estudado por Piaget em $A$ linguagem e o pensamento da criança 
(1923) passa exatamente pelas mesmas fases em relação ao tempo psicológico ou tempo da ação própria que os comportamentos de seriação ou de ordenação dos acontecimentos materiais no domínio do tempo físico: primeiramente intuitivo e não operatório, e substituindo simplesmente a percepção dos acontecimentos narrados pela sua representação mais ou menos exata ou mais ou menos imaginária e fabulosa e, em seguida, operatória ou lógica, passando a constituir uma seriação submetida ao raciocínio.

Torna-se necessário, então, ater-se ao fato de que existe um tempo operatório que consiste em relações de sucessão e de duração, fundadas em operações análogas às operações lógicas. De acordo com Piaget (1946), semelhante tempo operatório será distinto do tempo intuitivo, que é limitado às relações de sucessão e de duração dadas na percepção imediata, externa e interna.

É nesta mesma obra, A noção de tempo na criança (1946), que Piaget retoma os principais aspectos do "discurso" infantil, anterior aos 7-8 anos $^{2}$, para colocá-los em relação aos problemas da ordem de sucessão no tempo físico. Ele conclui que:

[...] é um unicamente o conteúdo do tempo, isto é, os acontecimentos como tais da realidade, exterior ou psicológica, que são irreversíveis, enquanto que o próprio tempo, como esquema organizador, consiste num sistema de operações reversíveis. Em particular, a ordem de sucessão, como seriação dos acontecimentos, uns em relação aos outros, supõe necessariamente um jogo de operaçóes suscetíveis de percorrer esses

2 "Se apresentarmos às crianças uma narrativa para reproduzir ou o começo e o fim de uma história a reconstituir (imagens de Dawid), ou ainda imagens em desordem para seriar uma história simples, reencontramos, com efeito, o que nos ensinaram os desenhos do capítulo I a propósito do tempo físico: exatamente como na vida quotidiana, quando uma criança de 2 a 4 anos quer contar um passeio, uma visita a amigos ou as aventuras de uma viagem, há um amontoamento incoerente de uma multidão de detalhes simplesmente justapostos, cada um dos quais se associa a um outro por pares ou pequenas sequências, mas cuja ordem geral escapa aos nossos hábitos mentais. Haverá nesse caso, simplesmente, falta de ordem para outrem, isto é, uma deficiência de exposição, ou a desordem da narração traduz o estado interior? Tudo o que sabemos das relaçôes entre o comportamento social e o comportamento intelectual da criança nos leva a supor que essas duas espécies de incoerências não são senão uma única, e é aprendendo a contar aos outros que a criança poderá contar as coisas a si mesma e organizará assim a sua memória ativa” (PIAGET, 1946, p. 286). 
acontecimentos, em pensamento, tanto no sentido regressivo quanto no progressivo, porquanto toda série implica dois sentidos de percurso ou de orientação, sem deixar, por isso, de ser assimétrica. Ou por outra, ordenar os acontecimentos é segui-los tanto na ordem "A antes de B; $\mathrm{B}$ antes de $\mathrm{C}$; ...etc.", como na ordem "C depois de B; B depois de A". Ora, para saber se $\mathrm{X}$ foi feito antes de $\mathrm{Y}$ ou ao contrário, é preciso remontar dos efeitos às causas, ou partir das causas para os efeitos, de acordo com todas as combinações possíveis, até que seja encontrada uma solução coerente com o conjunto das séries construídas: é neste sentido que a ordem das sucessões supóe a reversibilidade do pensamento (PIAGET, 1946, p. 288).

Observa-se, portanto, o quanto o tempo é solidário da causalidade: ele está para as operações explicativas como a ordem lógica está para as operações implicativas. Ele envolve a relação antecedente/consequente como necessária ao atribuir uma causa a um fenômeno. No caso das narrativas, a utilização de conectivo ou verbo indicando o vínculo causal, conforme mencionei anteriormente, sinaliza para essa capacidade de estabelecer relações causais entre os fatos da história. Dessa forma, a narração das crianças passa a realçar fatores que são necessários para a objetividade do pensamento, como as ligações de tempo (ordem) e causalidade que unem os acontecimentos da história. De forma análoga à causalidade sensório-motora do sexto estágio, a criança torna-se capaz de dedução causal ao reconstituir mentalmente a causa a partir de um efeito percebido na história ou, ao contrário, a criança pode ser levada a prever os efeitos, o que acontecerá na história, partindo de uma causa (PINHEIRO, 2004, p. 142).

No entanto, observamos que Piaget (1946) aponta para o fato de que essa solução coerente encontrada na ordem das sucessões supõe a reversibilidade do pensamento:

A partir dos 7-8 anos, ao contrário, as mesmas experiências permitem constatar uma outra atitude do espírito (com toda a continuidade entre as duas é necessário dizer). Preocupado com a ordem no tempo, o sujeito procura reconstituir os discursos segundo a sucessão mais simples e mais provável dos acontecimentos. Ele tomará em consideração o conjunto dos dados, relacionando-os num todo coerente, em vez de pulverizar 
o pormenor ou de se contentar com um todo imaginário. Capaz de reversibilidade, ele saberá refazer várias construções com o mesmo material e compará-las entre si, desdobrando-as em todos os sentidos: em suma, ele introduzirá no tempo psicológico como no tempo físico uma sucessão racional, por reconstrução operatória e não mais, unicamente, por reconstituição intuitiva. (PIAGET, 1946, p. 289)

Em seu estudo, Piaget (1946) conclui que existe um parentesco fundamental do tempo psicológico e do tempo físico já que as séries físicas e psicológicas se apoiam umas nas outras porque ambas são reconstituições de ordem causal. Ele explica que se a causalidade é o sistema total das operações que permite ligar os acontecimentos físicos uns com os outros, é claro que para estabelecer experimentalmente uma relação causal trata-se de colocar em relação as medidas sucessivas que tomamos e, por conseguinte, recorrer à nossa memória ou aos modos de reconstituição próprios do tempo psicológico. É nesse sentido que o tempo físico implica o tempo psicológico: só há coordenação dos movimentos exteriores relativamente à coordenação das ações do observador, e vice-versa (PIAGET, 1946, p. 320).

Destaco, ainda, a próxima ideia de Geraldi (1997) ao referir-se à atividade com textos como sendo uma atividade de produção de sentidos:

Trata-se agora de reconstruir, em face de uma leitura de um texto, a caminhada interpretativa do leitor: descobrir por que este sentido foi construído a partir das "pistas" fornecidas pelo texto. Isto significa se perguntar, no mínimo, que variáveis sociais, culturais e linguísticas foram acionadas pelo aluno para produzir a leitura que produziu ${ }^{3}$ (GERALDI, 1997, p. 112)

Podemos acrescentar a essa ideia o interesse dessa pesquisa ao perguntarmos, também, que variáveis cognitivas foram acionadas pelo aluno para produzir a leitura que produziu a partir das "pistas" fornecidas pelo seu texto. Nesse caso, estaremos pensando no aluno não somente como autor do próprio texto, mas também como leitor, o que implica tanto a interpretação

3 Grifo meu 
posterior que ele faz do que produziu como a interpretação que as outras pessoas (professor e colegas) possam vir a fazer do seu texto. A esse respeito, Ferreiro (2001) comenta que

É importante considerar que o dado que manejamos não é a folha produzida por uma criança. O dado é resultado das condições de produção, que podem ser muito diferentes. [...] O dado é: a intenção, $\mathrm{o}$ próprio processo de produção, o produto terminado (quando o produtor diz que acabou, que está pronto) e a interpretação que faz, uma vez que o produto está terminado conforme seu ponto de vista. (FERREIRO, 2001, p. 70)

Com relação à interpretação que outras pessoas possam vir a fazer do seu texto, Smolka (1992) e Góes (1993) destacam que:

Pesquisas mostram que a criança é pouco propensa à revisão espontânea e que, quando esta ocorre, se limita a alterações de aspectos de superfície (como questões ortográficas, flexôes), não afetando aspectos de base (como incompletude de enunciados, ambiguidade referencial). Esse é um motivo adicional para que as condições de produção incluam momentos de exame do próprio texto. (SMOLKA, 1992, p. 63)

A autora defende a ideia de se pensar o processo de produção de texto como um curso de eventos, desde o desencadeamento até a destinação e repercussão. Nesse curso, os processos interativos relevantes não dizem respeito apenas às relações professor-aluno, mas à interação entre pares. Ela afirma que a distinção entre gerar o texto e pensar sobre o texto não é manifestada imediatamente pelo escritor iniciante e que a criança mais nova não identifica com facilidade problemas em sua produção, como enunciados incompletos ou obscuros.

Para a autora, é no esforço de estabelecer tal distinção que começam a se refinar as funçôes comunicativa e individual da escrita. No que respeita à primeira, a criança começa a escrever provavelmente assumindo o destinatário apenas como alguém para quem faz o texto, em muitas de suas experiências de escrita. Em circunstâncias nas quais o destinatário é mais concretamente figurado, como na elaboração de cartas e bilhetes, a criança tende a uma produção mais dirigida para o outro mas, aí, aparecem 
passagens que, de novo, revelam marcas da fala, configuradas no uso de estratégias de conversação, como se o destinatário estivesse presente. Por essa razão, Smolka (1992) afirma que podem aparecer referências exofóricas (relativas a contextos não linguísticos e não partilhados pelo leitor) ou enunciados contendo relações não lexicalizadas. Segundo ela, a incorporação das exigências desse modo de interação, no qual o escrever e o ler não ocorrem no mesmo tempo e espaço, se dá gradualmente. Aos poucos, a criança passa a produzir ajustando o discurso às necessidades de informação e características do leitor e às peculiaridades do propósito de interação.

A função individual se estabelece, inicialmente, quando a escrita é feita para si, utilizada como recurso de memória (coisas para lembrar), de auto-organização (coisas para orientar) ou de fruição (coisas para expressar). Depois, também, a escrita para o outro assume uma função individual, de natureza bem mais complexa, ao permitir que o sujeito desenvolva uma atitude de análise ante seu discurso e pensamento. Nesse processo, a função comunicativa da escrita contribui para aprimorar a função individual, a de organizar e regular o próprio pensamento.

Em resumo, as duas funções se diferenciam e passam a se alimentar reciprocamente. São as condições de produção que vão possibilitar, em maior ou menor grau, essa diferenciação e o aumento de consciência das operações envolvidas na escrito (SMOLKA, 1992, p. 68).

Com base na suposição da relevância da presença de um interlocutor que represente o leitor e que conduza o escritor iniciante a desenvolver ações reflexivas na escrita, Góes (1993) implementou um projeto sobre abordagens de planejamento e de análise de texto em crianças na faixa etária de 8 a 13 anos, que frequentavam a primeira etapa do ensino fundamental de uma escola pública da rede municipal de Campinas, SP.

Os procedimentos envolveram entrevistas individuais, nas quais buscavam salientar para a criança o caráter dialógico do ato de escrever e induzi-la a alternar os papéis de escritor e leitor de seu texto. 
Com as solicitações de explicitação de enunciados foram verificadas as formas pelas quais o sujeito operava sobre problemas em enunciados de seu texto ao identificar e efetuar mudanças que julgasse necessárias ou que fossem sugeridas pela entrevistadora.

A sequência de procedimentos experimentados foi a seguinte:

- Explicitação individual. Esse procedimento foi realizado com doze alunos. Na sessão de análise, a criança era instruída a ler seu texto e indicar as correções necessárias; o apontamento de problemas deveria, desse modo, ser feito por sua iniciativa. Durante a instrução, a entrevistadora pedia-lhe que examinasse o texto pensando que este deveria ser compreendido por pessoas que não estariam próximas do escritor para resolver possíveis dúvidas. A tarefa era, então, identificar e efetuar alterações em pontos do texto que poderiam impedir a compreensão pelo leitor.

- Explicitação em duplas. Doze crianças (seis duplas) efetuaram a explicitação neste procedimento. As duas crianças eram solicitadas a ler e analisar conjuntamente seus textos, um de cada vez. A entrevistadora dava orientação para que buscassem melhorar o texto e sugeria à criança-leitora que indicasse para a criança-escritora as mudanças eventualmente necessárias para a maior clareza dos enunciados.

- Explicitação dirigida. Os dois procedimentos anteriores se mostraram úteis para mostrar os modos de análise de problemas do texto; contudo, em ambas as situações, as abordagens assumidas pelas crianças dispensavam a operação efetiva sobre aspectos da organização de enunciados. Para criar essa exigência, foi implementado o terceiro procedimento, no qual a entrevistadora apontava problemas a serem resolvidos e conduzia o diálogo de modo a favorecer a emergência da resolução. Nas instruções era enfatizado o propósito de melhorar o texto para o leitor. Os problemas examinados diziam respeito à coesão referencial, em enunciados que traziam dúvidas para a identificação do referente de formas remissivas, e à coesão sequencial, em enunciados que 
prejudicavam a manutenção e a progressão temática (envolvendo critérios levantados com base em indicações de Koch (1991) e Koch e Travaglia (1990).

Foram analisados textos de diferentes tipos: de narração ficcional, de descrição-caracterização e de descrição-explicação. Tais produções haviam sido realizadas para compor livros que seriam trocados entre as classes; os leitores potenciais eram, portanto, os colegas e a professora, bem como outros adultos e crianças da escola.

No que se refere ao conjunto de resultados relativos aos três procedimentos de explicitação, Góes (1993) constatou uma semelhança de critérios empregados na identificação de problemas textuais em situações de análise individual e análise com ajuda de um parceiro. A atenção era restrita à ortografia e eventualmente abrangia omissão de palavras e pontuação. A presença do parceiro-leitor fez emergir, no entanto, outros apontamentos, relativos à adequação do traçado e à flexão de palavras. Portanto, fosse individualmente ou em parceria, as crianças tendiam a ignorar problemas de organização de enunciados. Entretanto, elas conseguiam operar sobre os mesmos, com diferentes graus de êxito, quando se apoiavam nas orientaçóes dadas pela entrevistadora. Vejamos alguns exemplos:

- Enunciados com problemas de referencialidade - envolvendo o uso ambíguo de pronome pessoal ou referência a contexto extralinguístico não compartilhado pelo leitor.

Enunciado original: "Eu fui no circo e vi um palhaço e um cachorro, ele faz mágica”.

Explicitação: "Eu fui no circo e vi um palhaço e um cachorro, o palhaço faz mágica”.

- Enunciados incompletos - apresentando omissão de constituinte temáticos necessários à plena construção de sentidos.

As abordagens das crianças a esses tipos de problemas consistiram em dois tipos de solução. A primeira foi de completar o enunciado com os elementos temáticos omitidos.

Enunciado original: "E Pedro passou mais de dois meses". 
Explicitação: "E Pedro passou mais de dois meses sem ver seu cavalo".

A segunda forma de solução foi substituir o enunciado, ampliando os constituintes temáticos.

Enunciado original: "A valeta que puseram é muito alta e nem dá para os parar, eles passão com tudo".

Explicitação: "A valeta que puseram para parar os carros não é profunda e eles não para, ela não é bem feita”.

- Enunciados obscuros - carecendo de explicitação de relações entre suas partes.

As soluções foram análogas às abordagens verificadas perante enunciados incompletos. O primeiro tipo de solução foi adicionar enunciado(s), mantendo o existente.

Enunciado original: "Quando aquela rosa saiu de onde".

Explicitação: "No fim do programa no show da Mara a Marlinda diz um monte de versos tão lindos assim: Quando aquela rosa saiu de onde".

O segundo tipo de solução coincidiu com aquele mostrado frente a enunciados incompletos - substituir o enunciado, ampliando os constituintes temáticos.

Enunciado original: "Colocar rede fora de física para dar mais emoção".

Explicitação: "Se a diretora desse licença para as crianças colocar a rede fora da aula de física ia dar mais emoção".

Tomadas em conjunto, as análises de enunciados incompletos e obscuros indicam que a abordagem das crianças mais novas, na explicitação, correspondia, em geral, a acrescentar constituintes temáticos, isto é, a dizer mais; já as mais velhas mostraram-se mais propensas a dizer de novo. Esta última forma de operar sobre o texto, por vezes, resultava numa solução menos econômica, como se deu na correção de enunciados incompletos, mas revela um modo mais complexo de utilização de recursos de linguagem ${ }^{4}$ (GÓES, 1993, p. 110)

O que a autora não fala é que essa forma mais complexa de operar sobre o texto exige reversibilidade por parte do sujeito, conforme foi explorado anteriormente. 
De acordo com a autora, as formas de resolver os problemas nem sempre resultavam plenamente satisfatórias, sobretudo frente a enunciados obscuros; alguns sujeitos pareciam não compreender o que deveria ser compreendido. Apesar disso, o papel de "representante do leitor" assumido pela entrevistadora constituiu uma condição de ajuda para a busca de soluções, muitas das quais foram bastante adequadas, revelando capacidades emergentes no jogo das interações em torno do texto. Essas manifestações configuram-se, assim, através de participação do outro, que assumiu uma postura de negociação de sentidos frente aos enunciados do escritor iniciante.

A respeito da interpretação que outras pessoas fazem do texto da criança, resta-me reiterar, ao final desta seção, que embora esses estudos estejam apoiados numa concepção vygotskiana, podemos vislumbrar nos enunciados trabalhados pela autora (enunciados com problemas de referencialidade, enunciados incompletos e enunciados obscuros) as características da coerência e do todo numa perspectiva piagetiana, conforme apresentei anteriormente, se os relacionarmos com os conceitos de tempo, espaço e causalidade. Também podemos evidenciar que os movimentos de centração e descentração importam, sem dúvida, na consideração de interpretações da relação escritor-leitor e da constituição do autor, tendo em vista os diversos planos de dialogia implicados na produção escrita, os quais abrangem a relação da criança com vários outros: o outro para quem a criança diz (seus leitores); o outro de que toma palavras para dizer (seus modelos); o outro sobre quem diz (suas personagens); o outro que é participante do processo de produção do texto (pares e

Vejamos mais uma vez o que Piaget diz a esse respeito na obra A noção de tempo na criança (1946, p. 288): "Ora, esta dificuldade em reconstruir um outro discurso, portanto em voltar atrás para se empenhar numa outra direção, ou, de uma maneira geral, em considerar um discurso como simples hipótese que podemos, sempre que necessário, cancelar para conceber outros novos, resulta diretamente dessa irreversibilidade do pensamento dos mais jovens, sempre dirigido no sentido da ação, à maneira de uma pura experiência mental sem retorno possível nem mobilidade operatória: é a expressão mais significativa do caráter intuitivo e pré-operatório do pensamento primitivo". 
professores que atuam como comentadores, coautores, correvisores) etc. A essas instâncias de dialogia articula-se também a relação da criança consigo própria, como escritora e leitora de seu texto (GÓES, 1993, p. 115). A seguir veremos em que medida os tipos de narrativa podem vir a influenciar nesse processo de descentração do sujeito.

\section{Tipos de produção textual: a narrativa relato e a narrativa conto}

É certo que a Tese de Doutorado de Dalla Zen (2006) traz contribuições importantes para esse estudo ao tomar como foco as narrativas escolares infantis, especialmente no que se refere aos textos em sua montagem ${ }^{5}$.

De acordo com Dalla Zen (2006, p.183), a estruturação textual, em larga escala, através da narrativa relato, parece confirmar a utilização do recontar determinadas experiências cotidianas por meio da escrita, enquanto a narrativa conto foi uma opção para as histórias mais ficcionais, para aquelas com nó, com suspense, as quais implicaram uma resolução, portanto, um outro formato.

Ao apresentar exemplos de narrativa relato, a autora explica que relatos desse tipo são comumente reconhecidos como narrativas, porque as ações e acontecimentos estão inscritos em uma temporalidade. Entretanto, nem sempre essa sucessão de fatos, essas descrições narrativizadas apresentam um nó narrativo, o que corresponderia a uma maior complexidade estrutural.

Já na montagem da narrativa conto estão presentes outros elementos, às vezes até agrupados em um mesmo texto: o já mencionado nó narrativo; uma certa tensão provocada por uma perturbação, por um acontecimento problemático, um certo tom de suspense e, finalmente, a resolução de impasses e obstáculos (ADAM; REVAZ, 1997; apud DALLA ZEN, 2006).

A autora utiliza a palavra montagem no sentido de organização discursiva. 
Para discutir esses elementos da narratologia, muitos autores utilizam o esquema proposto por William Labov (1982; apud DALLA ZEN, 2006) que, reportando-se à narrativa oral, define a narrativa como um dos métodos de recapitular experiências do passado, combinando-se uma sequência verbal de orações com a sequência de acontecimentos. Esse autor apresenta elementos de uma estrutura narrativa em sua totalidade, que nem sempre estão presentes integralmente nos textos, apenas nos tipos inteiramente desenvolvidos. Segundo ele, uma narrativa completa pode apresentar os seguintes itens: resumo (orações introdutórias que resumem a história); orientação (sinalizadores de espaço-tempo, de personagens, suas atividades e situação); ação complicadora (conflito, nó); avaliação (retomadas, interrupções, comentários); resultado ou resolução (desfecho); coda (maneiras de identificar o final da narrativa). Sugere ainda que olhemos para uma narrativa como uma série de respostas a perguntas implícitas: a) resumo: foi sobre o quê?; b) orientação: quem, quando, o quê, onde?; c) ação complicadora: daí, o que aconteceu?; d) avaliação: e daí?; e) resultado: o que afinal aconteceu?

É interessante notar que todos esses elementos do esquema Laboviano reiteram a afirmação de que a narrativa conto corresponde a uma maior complexidade estrutural, sendo representativa dessa organização dita mais desenvolvida. Este ponto parece ser fundamental para a minha investigação, cabendo, então, a pergunta: E o que estaria por trás dessa estrutura de construção textual bem mais complexa da narrativa conto?

A resposta para essa pergunta parece estar relacionada com a própria natureza do conteúdo escrito pelo sujeito. Em minha experiência como professora costuma me chamar a atenção as inúmeras produções narradas na $\mathrm{I}^{\mathrm{a}}$ pessoa, decorrentes da própria experiência de vida dos alunos (narrativa relato). Outras produções, que narram assuntos diversos ou alguma "trama" a ser resolvida são bem mais raras e, quando aparecem, costumam ser de alunos que apresentam maior facilidade quanto à aprendizagem e/ou maior grau de letramento. 
Um dos fatores responsáveis pela coerência textual é o conbecimento de mundo adquirido à medida que vivemos e tomamos contato com o mundo que nos cerca (KOCH; 1990). A narrativa relato dos alunos está impregnada por esse conhecimento de mundo. Lembremos, no entanto, que o conhecimento dito científico - e aqui eu tomo como exemplo o gênero da narrativa conto aprendido nos livros de literatura infantil tanto em casa como nas escolas - nem sempre coincide com esse conhecimento de mundo, ocasionando limitações nas produções dos alunos e empobrecendo o seu mundo textual. Sim, porque uma coisa é ler e escutar uma narrativa conto, e a outra coisa é escrever uma narrativa conto. A primeira situação parece ser mais fácil que a segunda, porque os alunos costumam, de modo geral, compreender as histórias ao divertirem-se com elas e ao fazerem perguntas ou comentários apreciativos durante ou após a sua leitura. A segunda situação exige maior esforço intelectual, estando também relacionada com a capacidade cognitiva do sujeito. Poderíamos dizer então que a estrutura de construção textual bem mais complexa da narrativa conto envolve um maior nível de desenvolvimento das estruturas mentais do sujeito escrevente.

Podemos discutir, a partir da obra de Piaget (1951), de que forma os planos do real, do possível e do necessário interferem no pensamento do sujeito durante a construção de sua narrativa relato e de sua narrativa conto.

Ao que tudo indica, a narrativa relato dos alunos está relacionada basicamente com o registro do real, enquanto a narrativa conto relaciona-se com a capacidade de distanciar-se desse real para operar com hipóteses no plano do possível. Desta forma, a criação do nó narrativo ou do acontecimento problemático a ser resolvido na narrativa conto depende desse pensamento que tem como objeto o possível. Em outras palavras, é como se o aluno, ao escrever, perguntasse a si mesmo: "O que eu posso inventar que pode vir a ser um problema nessa história? E o que eu poderia inventar para resolver esse problema? Já sei! Pode ser isso, isso ou aquilo, mas se for a primeira ideia, posso resolver o 
problema inventando tanto essa como aquela solução. Se bem que essa solução seria mais estranha que aquela porque...”.

Segundo Garcia (1997), a mensagem de Piaget é que a chave para revelar o mistério da compreensibilidade do mundo é a criatividade: o mundo é compreensível somente na medida em que a mente cria os instrumentos para interpretá-lo. Ora, se toda verdadeira aprendizagem é um descobrimento e se todo descobrimento é uma recriação de uma realidade interpretada, a explicação dos mecanismos da criação do "novo" envolveria justamente essa capacidade de operar sobre simples possibilidades tratadas como hipóteses. É dessa forma que a humanidade desenvolve o conhecimento científico. E é por esse motivo que, enquanto a narrativa relato está impregnada pelo conhecimento de mundo do sujeito (plano do real), a narrativa conto está pelos mecanismos da criação do "novo", envolvidos no desenvolvimento do conhecimento dito científico (plano do possível).

A principal característica do pensamento formal está ligada, sem dúvida, ao papel que dá ao possível com relação às verificações de realidade: comparado ao pensamento concreto, constitui uma nova forma de equilíbrio:

Em resumo,o pensamento concreto continua fundamentalmente ligado ao real, e o sistema das operações concretas, que constitui a forma final de equilíbrio do pensamento intuitivo, chega apenas a um conjunto restrito de transformações virtuais, e, portanto, a uma noção do "possível” que é apenas uma extensão (não muito grande) do real. Este caráter do pensamento concreto é muito claro nas pesquisas aqui apresentadas, onde podemos comparar, em cada aspecto, o pensamento concreto da criança ao pensamento formal do pré-adolescente ou do adolescente; enquanto que estes últimos, para resolver o problema que lhes é proposto, começam imediatamente a construir um conjunto de hipóteses entre as quais precisarão escolher experimentalmente a melhor, a criança do nivel concreto a rigor não cria hipóteses. Age desde o começo, e apenas procura, durante sua ação, coordenar as leituras sucessivas dos resultados que obtém, o que significa estruturar a realidade na qual atua. Ou, se admitimos que cria hipóteses, é preciso esclarecer que estas são apenas projetos de ações possiveis, e não, como no adolescente, formas de imaginar o que deveria ser o real se tal ou qual condição hipotética fosse satisfeita. Grifo men (PIAGET, 1955, p. 188). 
É importante destacar que, com o pensamento formal, o real é que se subordina ao possível: os fatos só são explicados e admitidos como fatos depois de uma verificação que se refere ao conjunto das hipóteses compatíveis com a situação dada: em vez de apenas introduzir um início de necessidade no real, como ocorre nas inferências concretas, realiza desde o início a síntese entre o possível e o necessário, deduzindo com rigor as conclusóes de premissas, cuja verdade inicialmente é admitida apenas por hipótese, e, assim, vai do possível para o real (PIAGET, 1955, p. 189).

O domínio do possível, atingido pelo pensamento formal, deve ser considerado como a condição indispensável para a obtenção de uma forma geral de equilíbrio e como a condição não menos indispensável para a constituição de conexões necessárias, utilizadas pelo pensamento.

O esforço que é feito pelo sujeito no sentido de englobar relações aparentemente reais no conjunto daquelas concebidas por ele como possíveis nada mais é do que a busca pelo estabelecimento de uma coerência entre essas ligações. Novamente, notamos o quanto a causalidade encontra-se implicada nessas relações, conforme já expus anteriormente. Além disso, não podemos esquecer que, de acordo com Piaget (1955), o possível formal é o correlato obrigatório da noção de necessidade. Uma afirmação relativa apenas ao real não precisa ser necessária: a afirmação é verdadeira ou falsa, na medida em que corresponde ou não a um dado de fato. Uma dedução que se refere a uma hipótese, ou a um dado de fato, mas admitido como hipótese, é, ao contrário, necessariamente verdadeira, do ponto de vista formal, desde que seja correta, e isso independentemente do valor da hipótese admitida:

A conexão marcada pelas palavras "se... então" (implicação inferencial) consiste em ligar uma conseqüência necessária a uma afirmação simplesmente possível: é esta síntese do necessário e do possível que caracteriza o emprego desse possível no pensamento formal, por oposição ao possível extensão-do-real do pensamento concreto e às possibilidades não reguladas, características das ficções da imaginação. 
Ora, em que consiste este possível formal? É possível tudo que não é contraditório. Mas o não contraditório é, rigorosamente falando, o conjunto das transformaçôes reversíveis [...]. Assim, a reversibilidade operatória formal [...] adquire, nesta perspectiva lógica, a significação da necessidade dedutiva. (PIAGET, 1955, p. 193-194)

Podemos dizer então que, quando o enredo de uma narrativa conto apresenta elementos contraditórios, estamos diante de uma irreversibilidade operatória, traduzida sob a forma de incoerências locais, cujo acúmulo pode tornar o todo do texto incoerente conforme vimos anteriormente.

\section{A análise inicial dos dados}

A investigação deste estudo de doutorado foi realizada com sujeitos pré-adolescentes que frequentavam, no ano de 2008, o $5^{\circ}$ ano de escolaridade, em escola pública da Rede Municipal de Ensino, em Porto Alegre.

Com a finalidade de verificar o que vem emergindo dos dados já coletados, selecionei o registro dos 6 primeiros encontros, realizados nos meses de junho, julho e agosto de 2008, para fazer uma leitura mais atenta das condutas das alunas em relação aos aspectos cognitivos durante o processo de construção da coerência nos textos narrativos. As tarefas propostas nesses encontros foram as seguintes: $1^{\mathrm{a}}$ ) recontar oralmente e por escrito a história $A$ operação do tio Onofre, de Tatiana Belink, lida pela professora pesquisadora; $2^{\mathrm{a}}$ ) ler a própria história recontada por escrito no encontro anterior e, a seguir, em duplas ou trios montar a história $A$ operação do tio Onofre numa cartolina. Cada trio recebeu 13 tiras de papéis contendo todas as partes da história do livro (Anexo I); $3^{\mathrm{a}}$ ) imaginar e escrever individualmente uma história utilizando as informaçóes de um quadro sobre a perda da casa de dona Renata (Anexo II); $4^{\mathrm{a}}$ ) em duplas tinham que melhorar a história produzida no encontro anterior pela colega, identificando e resolvendo problemas em pontos do texto que pudessem impedir a compreensão pelo leitor. Para a realização 
dessa última tarefa foram necessários três encontros, cada encontro com uma dupla de alunas.

Tendo em vista que as condutas das alunas estão relacionadas com suas próprias produções escritas e com as produções escritas de suas colegas e, ainda, que os termos de busca referidos por mim envolvem duas áreas, a cognição e a linguística, foi necessário organizá-los dentro de duas categorias iniciais: Processos mentais e Coerência e coesão textuais.

Apresentarei a seguir esta primeira análise que faz parte de um quadro-síntese que reúne os dados de todas as alunas. Para fins de ilustração, selecionei duas alunas, a Sheila (12 anos) e a Stela (11a $8 \mathrm{~m}$ ), as mesmas que trabalharam juntas na tarefa de montar a história $A$ operação do tio Onofre e na tarefa que propus de melhorar a história produzida pela colega em pontos do texto que pudessem impedir a compreensão pelo leitor.

As histórias produzidas por elas a partir das informações de um quadro (Anexo II), foram transcritas pela professora pesquisadora, conforme observamos nas figuras a seguir: 
Era uma uma vez uma família de 6 filhas que estavam sentados sentados na sala vendo televisão e o marido guilherme lembrou que não tinha pagado o alugeu e estava chuvendo muito forte e bateram na porta e o marido dela foi abrir a porta para ver quem era que estava batendo na rua e as filha perguntaram para o papai primeiro foi a Anielle pai quem é depois a jamile e a camila depois a Stéfane e a rafaela e a flávia.

E ele falou que nos estavamo sendo dispejado e a Aniele perguntou o que era ser dispejado e o pai dela esplicou para a seis filhas que ser dispejado era que nos temos que deixa a mosa casa e a jamilia falou: - Nos vamos deijar a mosa casa Não vai ser dispejado e de pois ele saíram de casa no outro dia o moso voutou para eles sairem dela mas a dona Renata já estava pensando que com a popansa que eles tinham guardado para fazer os quinze anos da rafaela mas como nos estávamos presisando ela compro uma casa nova para eles moraro tinha uma cozinha, pátio, dois quartos, um banheiro, e sala de jantar e tudo mais ela na casa nova era muito melho tinha tudo que eles queriam até cozinha completa, os quarto com aconchego para as filha todas o pátio nem se fala era muito bom era grande demais du ate para botar uma piscina de chão para mós tomar banho e depois eles foram viajar e ficaram felizes para sempre com as suas filhas.

FIM !!!

Fig. 1: Transcrição da história "O alugeu duma casa", de Sheila (12 anos). 


\begin{abstract}
A perca da casa
Era uma vez uma familha que tinha comprado uma casa e o ceu marido estava desenpregado e eu estava. trabalhado de fachineira e tinha 5 filhos que se chamavam matheus, Anderson, douglas, gabriel e biel e 5 filhas Amanda, shayane, Aniele, camila, Jamile

E eles foran pasiar com a seus pais numa praia linda e ficaram ate tarde e eles voutaran as 4 oras da tarde e chegaram emcasa e a dona do terreno falou que eles estavam devendo 10 meses de alugel.

E eles tinham que sair logo ela pediu para ficar uma noite ea manha e o dono dise que eles podiam ficar ate o marido dela arumar um servisio e omarido dela consegu comprar uma casa que tinha pátio, 12 quartos, cozinha, dois banheros e sala de jantar era de dois andares e eles viverão felizes para sempre.
\end{abstract}

Fig. 2: Transcrição da história "A perca da casa", de Stela (11a 8m).

\section{Sheila (12 anos)}

Em relação aos processos mentais de Sheila observei que ela não costuma explicitar o "como" das tramas nas histórias trabalhadas. Isto aconteceu mais de uma vez: inicialmente, em seu reconto por escrito da história A operação do tio Onofre, ao "pular" de uma parte para outra da história omitindo tanto a parte que dá início à trama (chegada dos ladrões na casa de Talita) como a parte final da trama (participação do pai de Talita no desfecho da história); depois, ao encontrar dificuldade para ordenar as tiras com as partes desta mesma história, especialmente a $9^{\text {a }}$ tira (diálogo dos ladrões após o telefonema do pai de Talita) e, ainda, ao não se importar em buscar o "como", também inexistente, na história de Stela - quando indagada sobre como o marido de dona Renata conseguiu comprar uma casa se ele estava desempregado, ela respondeu: "Depois ele conseguiu". 
Apesar de dizer que entendeu a história escrita pela colega, Sheila necessitou de minhas perguntas para conseguir recontar oralmente, respondendo com compreensão, inclusive, a parte do "como":

E por que mesmo que eles perderam a casa? Não pagaram o aluguel dos 15 meses! E aí? A história termina triste, feliz? Feliz. Por quê? Depois os dois começaram a trabalhar e ai eles compraram a casa. Construiram a casa. (acrescenta informações sobre "como" conseguiram comprar a casa, na história de Stela).

Esta falta de conservação de partes da história para conseguir recontar oralmente e por escrito foi evidenciada tanto em textos alheios como em relação a suas próprias produções escritas. A esse respeito, podemos incluir o exemplo que segue:

Após as alterações que a colega fez em seu texto, Sheila solicitou ajuda para conseguir coordenar o que havia escrito anteriormente em sua história com o que acrescentaram de modificações, demonstrando, mais uma vez, dificuldade em conservar as partes antigas que deveriam ser mantidas com as partes reformuladas pela colega em outra folha: "Tem que riscar isso aqui, sora? Até casa? Onde começa? Desde ali do começo, sora?”.

Quanto ao aspecto da ordenação, referido anteriormente em relação à montagem das partes da história, cabe lembrar que ele está intimamente ligado ao conceito de tempo, ou seja, com a parte que vem antes e a parte que vem depois. Além disso, a dificuldade de Sheila em relação ao conceito de tempo também se manifesta através da sua indiferença a palavras inadequadas que expressam o tempo imediato nas histórias, ao invés de expressarem um futuro já considerado passado. Isto ocorre em duas situações: na primeira, quando ela escreve $e$ o ladram falou para a talita sentar no sofá 'agora' e a talita sentou; na segunda situação, quando pergunto como elas poderiam dizer, ao invés de "amanhã" já que sabemos que não será amanhã e que isso já aconteceu na história, Sheila faz um pequeno silêncio e, a seguir, responde: "Semana que vem!" (acha graça). Explico que existe o dia anterior e o dia seguinte, e ela diz: "Seguinte". 
Ao que tudo indica, as relações estabelecidas por Sheila na conservação parte-todo, que também envolve a ordenação (conceito de tempo), são ainda insuficientes para ela compreender a totalidade das histórias, tendo em vista suas falhas, que aparecem de forma sistemática na explicação das tramas das histórias.

Além disso, o fato de não conseguir compreender uma parte da própria história, como veremos a seguir, denota sua dificuldade na distinção das falas do narrador e dos personagens, justamente por não conseguir coordenar diferentes perspectivas, ou seja, a perspectiva do narrador, a dos personagens e a do leitor: "Essa parte eu não entendi nada, sora: ...e a Anielle perguntou o que era ser despejado e o pai dela explicou para os seus filhos que ser despejado era que nós temos que deixar a nossa casa e a família falou...”.

Sua incapacidade para coordenar tais perspectivas acaba se refletindo na falta de pontuação e acarretando dificuldades para a compreensão do texto pelo leitor.

Em relação à coerência e coesão textuais, é interessante observar que essas foram afetadas pelo pouco uso da pontuação nas histórias de Sheila, mesmo que quando indagada ela tenha respondido sobre os pontos necessários para serem empregados no diálogo de sua história (interrogação, travessão...): "Aqui ó, bota travessão aqui” (mostra o local para a Stela).

Sua reflexão sobre o ponto final vai do erro ao acerto. Após errar três vezes o lugar do ponto, cortando as frases, começa a acertar com a minha intervenção:

Indago onde vai o ponto em: $A$ dona Renata pediu para ficar uma noite e o dia seguinte... e a... e a dona..., responde: "Dona" (errado). A Stela diz para ela que não. Quando eu leio para descobrirem, fazendo uma paradinha após a palavra seguinte, a Sheila diz: "Seguinte". Ponto no seguinte, né sora?"

Quando elas lêem: E o marido dela conseguiu um serviço e comprou uma casa... a Stela diz "ponto", e eu pergunto: Será? Como é que continua? A Sheila diz: "Não tem ponto". Ela lê o restante da frase com a Stela: “...que tinha...11 quartos...cozinha, dois banheiros e sala de jantar...era de...”. Quando pergunto onde vai o ponto, a Sheila diz: "No jantar?" (certo). 
O fato de Sheila afirmar não ter compreendido a própria história acaba resultando na modificação de palavras que alteram ainda mais o sentido para a compreensão da história (moso por nós, embora deva ser "moço"). Quando a Stela se depara com a palavra moso, Sheila diz para ela que é "o nosso". Elas leem juntas e ficam em dúvida quanto à palavra cuja grafia está moso no texto. Então a Sheila diz: "É nosso. Viu como ta certo? (insiste com a Stela mesmo não estando certa e mesmo que a Stela e eu a questionemos). Não, ta certo".

Da mesma forma que insiste na palavra nosso, mesmo não estando adequada no texto, também ignora o seguinte enunciado obscuro de seu texto: dispejado.

E a familia falou: - Nós vamos deijar a mosa casa Não vai ser

Quando indago o que ela quis dizer nesta frase, ela responde: "Ah, eu também não me lembro. Nem me lembro da história que a gente tava fazendo".

Estas reações de Sheila apresentam a sua dificuldade para levar em consideração elementos do próprio texto que afetam a compreensão do leitor. Não basta, portanto, constatar um fato para aceitá-lo se houver razões para recusá-lo ou, se se preferir, recalcá-lo (PIAGET, 1974). Ao recusar os fatos conflitantes, Sheila mostra desinteresse em querer superá-los, uma vez que esses não se tornaram incômodos para ela.

Em resumo, podemos dizer que a não-conservação das partes da história e da sequência temporal, a falta de demarcação nas vozes do narrador e dos personagens e, ainda, a dificuldade na busca de sentido de algumas frases da própria história revelam o caráter irreversível e pré-operatório das relações percebidas ou estabelecidas pela Sheila em relação às histórias.

O fato de não conseguir conservar a totalidade da história significa que ainda não construiu os conceitos ligados ao tempo, ao espaço e à causalidade, fundamentais para o estabelecimento de relações entre os fatos e partes da história, assim como para o uso de elementos lingüísticos de coesão e para o uso das inferências 
na compreensão dos textos. Significa também que sua escrita de histórias permanece centrada em si mesma, porque ao escrever ignorando o uso da pontuação, desconsidera tanto o outro para quem diz (seus leitores), como o outro sobre quem diz (suas personagens). Em função destes aspectos, sua intenção comunicativa inicial não se concretiza, dificultando, portanto, o sentido do texto para o leitor (mesmo que a leitora seja ela própria!).

Assim, a incoordenação de todas as perspectivas aqui apresentadas prende-se à irreversibilidade própria à intuição ou à percepção imediata. Daí decorre a dificuldade de Sheila de unir operatoriamente os fatos e partes da história de forma integrada.

\section{Stela $(11 \mathrm{a} 8 \mathrm{~m})$}

Apesar de Stela ter ingressado no grupo a partir do segundo encontro, conseguiu acompanhar as tarefas propostas referentes ao primeiro encontro, pois conheceu a história $A$ operação do tio Onofre através de meus comentários a respeito e das ilustrações do livro que mostrei a ela. Também leu silenciosamente o reconto por escrito de Raquel. Ao colocar as partes dessa história em ordem, necessitou da minha intervenção, tendo que destrocar as tiras algumas vezes: E depois disso? "Aquela que diz que eles tão vendo televisão" (pega a $10^{a}$ tira/errado). Solicito que leiam para ver se é a tira correta: "Está certa. [...] Os policiais são o último.

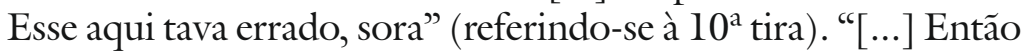
aqui não tem o alô" (referindo-se à $6^{\mathrm{a}}$ tira, depois de ler a $5^{\mathrm{a}}$ tira que ainda não colocou).

Em relação aos processos mentais, observei que à medida que os encontros foram se sucedendo, Stela foi se envolvendo cada vez mais nas propostas e manifestando esforços no sentido de conseguir realizar as tarefas da melhor forma possível. Durante o desenrolar das tarefas foi se conscientizando de suas dificuldades e solicitando ajuda para superá-las. Ao contrário de Sheila, a Stela agiu ativamente e não conseguiu "sossegar" enquanto não resolveu os problemas com os quais se confrontava. 
Ao analisar a própria história sobre a perda da casa, afirmou não haver entendido e não ter feito a história com todas as informações do quadro. Ela fez a história, mas não sabia de quem era o marido a quem se referiu no texto: "Eu fiz a história e eu não sei...”. Após observar o quadro, perguntou: “Tem que botar o nome da, do, do... marido?”. Manifestou uma certa confusão quanto aos personagens, já que omitiu a dona Renata para incluir-se no lugar dela na história. Após minha intervenção a esse respeito, deu-se conta de que estava contando a própria história ao escrever "eu": "Eu, dona...dona Renata? Pior, eu não botei o nome! [...] Eu tô contando a minha história se eu tô botando eu". E é a tua história? "Não!" (acha graça) Foste tu quem perdeu a casa? "Não!" (continua achando graça) "E a Renata... Botá assim?”.

Situação semelhante aconteceu ao analisar a história de Sheila. Quando indagada, incluiu-se na história, provavelmente porque uma das filhas (personagem) tinha o seu nome. Ela riu e modificou nós por todos: "Todo mundo estava sendo despejado. Todos". Quando eu li novamente o trecho que dizia ...era que 'nós' temos que deixar a nossa casa, perguntei se estava bom assim: "Ta! (responde baixinho). Pequeno silêncio. "É todos. Nós todos" (retorna à perspectiva do nós, incluindo-se na história).

A Stela também não se importou com o "como" em sua história, apenas quando questionada: "Ele conseguiu. Há uns dois mês atrás ele conseguiu!”. Respondeu que não explicou "como" em seu texto (pequeno silêncio). Quando perguntei onde é que teria que colocar esta explicação, ela localizou no texto: “... e o marido dela conseguiu, conseguiu comprar...). Após pensar "como" o marido de dona Renata conseguiu comprar uma casa se ele estava desempregado, leu: "Conseguiu um serviço. Daí depois bota comprar" (sugere acréscimo no próprio enunciado).

É interessante observar essa tendência de Stela em permanecer ligada à perspectiva do "eu" e do "nós", tanto em relação aos personagens da sua própria história como em relação aos personagens da história de Sheila. Além disso, o fato de utilizar 
apenas a voz do narrador em sua história parece ter sido um elemento facilitador na melhoria do próprio texto, se compararmos com a análise que ela teve que fazer da história de Sheila, que envolvia de maneira confusa as vozes misturadas do narrador e dos personagens. Provavelmente seja por isso que ela tenha afirmado que só consegue ver se a história dela está errada, a dos outro não.

Dessa forma, em relação à coevência e coesão textuais, consegue analisar sua própria pontuação quase inexistente (vírgulas em listagem de nomes, ponto ao término da listagem) e refletir sobre a pontuação durante minha leitura em voz alta do seu texto, interrompendo-me para dizer onde vai o ponto final nas frases, embora ainda não coordene ponto final e letra maiúscula no início das frases seguintes. Enquanto lê, arruma palavra no feminino para manter coerência com o parágrafo anterior em seu próprio texto: "[...] e a dona Renata pediu para ficar uma noite e a manhã e o dono [...] É a dona (referindo-se à dona do terreno no parágrafo anterior) É só botar um $a$ aqui” (arruma a letra $a$ na palavra). Ela também incluiu "e" como elemento de coesão na escrita da parte do "como", em seu próprio texto: “...um serviço. $E$ comprou... É né? Tem que botar um $e$ aqui: $e$ comprou uma casa..." (conseguiu um serviço 'e' comprou uma casa).

No entanto, foi justamente ao analisar a história de Sheila que a Stela se viu forçada a se colocar na perspectiva da autora para compreender o texto da colega. Solicitei que ela relesse o texto para entender. Ainda assim, necessitou de minha intervenção para recontar a história, pois afirmou não ter entendido "quase nada". Após responder as minhas perguntas sobre a história, tendo consultado o texto algumas vezes para respondê-las, disse, de forma duvidosa, que dava para entender. Conseguiu, então, localizar respostas às minhas perguntas no texto da colega, quando indagada sobre algo que não lembrava bem ("por que"): A Sheila chega a dizer por que elas tiveram que deixar a casa, por que eles vão ser despejados? "O pai dela esqueceu de... pagar o aluguel [...] Eu sei que é quando ãn... bateram na porta. Aqui 
ó: ...o marido Guilherme lembrou que não tinha pagado o aluguel e estava chovendo muito".

A Stela percorreu um longo caminho para compreender a parte do diálogo da história de Sheila em que não havia pontuação, não conseguindo fazer inferência, de saída, a partir de frases e trechos anteriores que estavam no texto (conceito de tempo: ordenação entre as partes da história):

Indago como é a pergunta que a Sheila escreveu, e ela responde: "quem é depois? A Jamile?" (mantém a ideia anterior/ errado). Necessita de minha leitura para refletir sobre a pontuação inexistente: $E$ as filhas perguntaram para o papai. Primeiro foi a Anielle: - Pai, quem é? A Stela diz: "A Jamile". Continuo lendo: Depois... Aqui é nova frase? E ela responde: "Aqui ó: e depois. Não! Quem é (afirma mudando de idéia sobre o local do ponto). Pequeno silêncio. Indago onde ela tinha colocado o ponto: "Eu tinha botado junto com o $e$ ". Pergunto se é antes ou depois do $e ́$, e ela responde "Depois [...] Quem é? Quem. Tem que botar no é, né sora?”.

Aos poucos, vai melhorando sua compreensão em relação a esta parte do diálogo após ler em voz alta e identificar o local do ponto de interrogação na frase: "Depois a... depois a Jamile (lendo) Não entendi também, sora... a Anielle e depois a Jamile? (pequeno silêncio) As duas perguntaram pra ele? Primeiro foi a Anielle e depois a Jamile? (agora parece compreender) Primeiro foi a Anielle que falou pra ele: quem era?”

Assim, Stela passa a sugerir e a planejar a alteração nesta parte do diálogo em outra folha após ter compreendido: “[...] a filha perguntou para o papai. Primeiro foi a Anielle que perguntou" (sugere as duas últimas palavras). A seguir, antecipa o que escreverá, buscando a confirmação da colega: "Papai, quem é que tava batendo na porta? [...] Ta, mas o pai dela não falou? (fica em dúvida). Quando indago se no texto ele falou, verificam que não. Pergunto se querem mudar isso e colocar a resposta do pai: "Eu quero. [...] Olha o que eu botei: Depois foi a Jamile que perguntou Pai quem era? [...] A Jamile e a Camila. Ah! E foi todo 
mundo que perguntou, sora! A Camila, depois a Stela, depois a Flávia, depois a... Rafaela. Todo mundo". Ela me responde que não quer colocar uma filha de cada vez perguntando, mas tentar explicar que todas perguntaram: "E depois todas perguntaram para o papai" (diz para mim).

O papel da leitura em voz alta e os meus questionamentos em relação à pontuação parecem ter exercido uma influência positiva na melhoria da sua compreensão em relação à parte do diálogo na história, pois ao conseguir distinguir as falas dos personagens, Stela conseguiu colocar-se em outros pontos de vista, melhorando sua capacidade de descentração ao estabelecer novas relações em função de regulações mais ativas.

Em relação a um enunciado obscuro do texto de Sheila $-E$ a familia falou: - Nós vamos deixar a nossa casa Não vai ser dispejado - Stela dá a sua ideia acrescentando uma palavra na frase. A frase fica com sentido, mas não dentro da totalidade da história: "Ai, eu não entendi isso! [...] Não vai ser difícil ser dispejado" (pequeno silêncio) "Ah, eu não entendi. Sheila... Tu vai ter a ideia e me fala que eu vou escrever!” (acha graça) “[...] Acho que ela quis botar nós vamos ser despejados?” (coloca-se no lugar de Sheila para dizer como Sheila teria pensado ao escrever) Pequeno silêncio. "Eu acho que ela quis botar isso, sora".

Vemos, nesse exemplo, que Stela consegue resolver a incoerência local existente no texto de Sheila ao colocar-se no ponto de vista da autora. Em seguida, ela manifesta avanço no aspecto da ordenação entre as parte da história, pois consegue coordenar as alteraçôes que fez na história com o que a Sheila havia escrito antes. Ela passa a indicar, então, o que deverá permanecer e o que deverá ser suprimido na história:

"Ele falou que... aqui ó, é o que eu acho, sora (afirma indicando o início do parágrafo para riscar) A Jamile, e a Camila, a Stela, a Shayane (responde até onde deverá riscar no texto de Sheila). É, aqui tem que riscar também. Aqui ó... que ele, ele... [...] E ele falou...[...] Apagar aqui, né sora? Aqui: [...] que ser despejado...”. 
No entanto, Stela apresentou oscilações no que se refere à busca de sentido no texto de Sheila, o que confirma a falta de estabilidade na conservação de todas as partes da história, conforme comentei anteriormente em relação à sua incapacidade de inferir sobre o diálogo da história a partir de frases e trechos anteriores. Assim, mesmo que tenha conseguido ler com compreensão palavras que estavam inadequadas no texto de Sheila, sugerindo substituições durante a leitura - "[...] era que nós temos que deixa a mosa... A mossa? É nossa!"; "Na rua? Na porta!"(para o trecho que diz quem era que estava batendo na rua...) - nem sempre conseguiu êxito, conforme mostram as passagens abaixo relacionadas com a segunda leitura que fez do texto de Sheila:

Durante sua leitura do texto, Stela tenta buscar sentido em função de uma palavra trocada pela colega (colega errou). Ao substituir a palavra por outra, a frase fica com sentido, mas não dentro da totalidade da história: "E o nosso voltou, Sheila? (chama a atenção de Sheila para o fato de que fica sem sentido assim). E nós voltemo, sugere como deve ser para ter sentido: $\mathrm{E}$ no outro dia nós voltemo".

Quando intervenho e afirmo que é moço, ela continua a leitura refletindo novamente sobre esta passagem ao final do encontro:

"Saíram de casa e ele voltou? Eu não entendi. Então eles tavam em casa e o moço voltou pra eles saírem de casa. Ou eles foram passear e o [...] Como assim? Eles tavam em casa e o moço... bateu e entrou... [...] O moço voltou [...] O moço voltou pra eles saírem de casa [...] E no outro dia o moço voltou" (após refletir sobre o trecho: - Nós vamos deijar a mosa casa Não vai ser dispejado e depois ele saíram de casa no outro dia o moso voutou para eles sairem dela).

Tenta buscar sentido na leitura do texto da colega: substitui "ma casa" por "minha casa". A frase fica com sentido, mas não dentro da totalidade da história.

Embora essas passagens tenham sido anteriores ao progresso manifestado por Stela no decorrer de nossa conversação, 
podemos observar o quanto suas alterações em busca de sentido do texto permaneceram, inicialmente, ligadas à perspectiva do "nós" (nós voltemo) e do "eu" (minha casa). Essa tendência de incluir-se nas histórias parece dificultar sua reflexão sobre os personagens, pois não conseguiu sugerir, também, outra palavra que pudesse substituir Renata de forma a não repeti-la na história (ela, por exemplo). Disse não saber e ficou pensativa.

Não podemos esquecer que esta tendência de incluir-se nas histórias está relacionada com o processo que conduz do egocentrismo à descentração, já que nem sempre Stela consegue relacionar os objetos, personagens e o ambiente no qual eles estão inseridos na totalidade da história. Sabemos que esse caminho da descentração inclui o "remanejo de perspectivas", a capacidade de se desprender de um aspecto delimitado do real considerado até então para se levarem em consideração outros aspectos para serem coordenados, como a articulação entre as partes da história durante a sua elaboração e compreensão.

Em resumo, podemos dizer que o fato de Stela não explicitar os personagens e o "como" dos acontecimentos na história significa que também náo construiu os conceitos ligados ao tempo, ao espaço e à causalidade, importantes para a conservação da totalidade da história, inclusive para que tivesse conseguido recontar sozinha a história da colega. Em função dessa nãoconservação das partes da história, ela não conseguiu, inicialmente, fazer inferência a partir de frases e trechos que estavam no texto de Sheila, nem tampouco substituir palavras inadequadas nas frases escritas pela colega para que fizessem sentido dentro da totalidade da mesma história. Quando substituía, tais alterações permaneciam ligadas ao "eu" e ao "nós”, apresentando a mesma tendência anterior de incluir-se na narração como personagem, ficando presa na própria perspectiva em vez de levar em consideração outros aspectos para serem coordenados.

Apesar de manifestar esse pensamento pré-operatório em tais situações, apresentou um esforço significativo tanto na melhoria da própria história para o leitor - ao analisar sua 
pontuação praticamente inexistente e passar a utilizá-la durante a leitura do texto, ao acrescentar o nome da personagem e o $e$ como elemento linguístico de coesão para explicitar o "como", ao arrumar uma palavra no feminino para manter coerência com o parágrafo anterior - como ao buscar compreender o texto da colega. Nesse caso, ao colocar-se na perspectiva da autora para compreender a história, Stela conseguiu melhorar sua capacidade de descentração ao estabelecer novas relações em função de regulações mais ativas. Dessa forma, ela manifesta avanços quando consegue: localizar respostas às minhas perguntas no texto da colega; resolver a incoerência local existente em enunciado obscuro do texto; distinguir as falas dos personagens na parte do diálogo sem pontuação ao identificar o local do ponto de interrogação nas frases; sugerir e planejar (antecipar) sua modificação por escrito desta parte do diálogo após tê-lo compreendido; coordenar as modificações que fez na história com o que já havia sido escrito pela colega.

O esforço de Stela para compreender a história da colega envolve uma construção que constitui o início da coordenação de outros pontos de vista que passam a desligá-la do "eu”. Esse desligamento assinala o início das operações propriamente ditas, devidas à reversibilidade progressiva do seu pensamento.

\section{Sheila e Stela}

A minha primeira impressão ao desenvolver o trabalho com essa dupla de alunas foi equivocada. De tanto escutar a Stela dizer que não entendia a história de Sheila, passei a atribuir-lhe uma dificuldade maior que a da própria Sheila.

O fato é que ambas encontram-se praticamente na mesma etapa de construção da coerência nas narrativas, embora se diferenciem por um aspecto que considero extremamente significativo: enquanto a Sheila se mostra desinteressada em querer superar pontos conflitantes para o leitor em sua própria história, 
a Stela busca resolvê-los apresentando progressos na ação através de regulações ativas.

É por isso que a Stela "rouba" a cena e passa a destacar-se mais que a Sheila durante as tarefas propostas, transmitindo a falsa impressão de ter mais dificuldade que a colega, além de ter me levado à exaustão quando consumiu a maior parte do tempo de nossa conversação com a questão da pontuação que eu considerava irrelevante para o problema de pesquisa.

\section{Conclusões}

Essa primeira análise dos dados de Sheila e Stela mostrouse produtiva para os objetivos da pesquisa e aponta para as seguintes premissas que orientam as minhas ações enquanto professora-pesquisadora:

- As ligações temporais, causais e lógicas estiveram relacionadas com as características do texto que diziam respeito à coerência e ao todo, sob o ponto de vista da organização no pensamento. A esse respeito vimos que a Sheila e a Stela apresentaram dificuldades para conservar o todo por não conseguirem relacionar os fatos e partes da história de forma integrada.

- A necessidade que surgiu de explicarem para o leitor as situações que ocorriam no decorrer da história, de forma a descrever e relacionar os objetos, personagens e o ambiente no qual eles estavam inseridos, esteve relacionada com o processo que conduz do egocentrismo à descentração. Podemos mencionar aqui tanto os acréscimos que elas fizeram nos enunciados incompletos como o acréscimo da pontuação nos textos analisados.

- A interpretação posterior que as alunas fizeram das suas próprias produções e do texto da colega auxiliou tanto na identificação como na solução de problemas na produção de cada uma, além de ter fornecido dados 
sobre as formas pelas quais elas operavam sobre problemas que afetavam a coerência em enunciados de seus textos. A esse respeito, evidenciamos o quanto a interpretação de Stela em relação ao texto de Sheila foi importante para a melhoria da história para o leitor.

- O uso de elementos coesivos dá ao texto maior legibilidade, explicitando os tipos de relações estabelecidas entre os elementos linguísticos que o compõem, os quais ganham sustentação quando analisados na perspectiva piagetiana, através dos conceitos de tempo, espaço e causalidade. A esse respeito podemos mencionar que tanto a falta como o mau uso dos elementos linguísticos de coesão em determinadas partes da história indicam a dificuldade de Sheila e de Stela para estabelecerem relações causais entre os fatos da mesma história.

- As atividades que envolvem a cooperação tornam-se necessáras na busca da superação de possíveis problemas de coerência evidenciados na produção textual. Embora a Sheila não tenha tido o mesmo grau de participação na superação dos problemas de coerência evidenciados em sua história, deixando a Stela resolvêlos com o auxílio da professora-pesquisadora, podemos pensar nos benefícios trazidos por um trabalho quando a troca entre pares se dá efetivamente.

- Se a construção da coerência decorre de uma multiplicidade de fatores das mais diversas ordens (linguísticos, discursivos, cognitivos, culturais e interacionais), então podemos estabelecer pontos de encontro com a Epistemologia Genética também no que se refere à construção das categorias de análise. A esse respeito, pretendo aprimorar os meus termos de busca e as minhas categorias iniciais de análise, de forma a integrálos sob o ponto de vista linguístico e cognitivo. 
- A narrativa relato está impregnada pelo conhecimento de mundo do sujeito (plano do real) e a narrativa conto relaciona-se com a capacidade de distanciar-se desse real para operar com hipóteses no plano do possível. Vimos o quanto foi difícil para a Stela desligar-se do "eu" e do "nós" numa proposta de produção de narrativa que não era a narrativa relato. Podemos interpretar o seu esforço na superação deste problema como fazendo parte de um caminho evolutivo a ser percorrido por ela desde as noções até os conceitos.

- A coerência está relacionada com todos os possíveis não contraditórios, ou seja, com o conjunto das transformações reversíveis. A esse respeito observamos a irreversibilidade no pensamento de Sheila, ao deparar-se com incoerências locais da própria história, e um início de reversibilidade no pensamento de Stela, ao conseguir resolver o enunciado obscuro na história de Sheila.

Para finalizar, podemos atribuir alguns pressupostos para os avanços da Stela e das demais alunas. Ao que tudo indica, para que ocorram avanços cognitivos no sujeito, a leitura e a interpretação exercem um papel fundamental na melhoria da capacidade de descentração e, consequentemente, na diferenciação entre: $O$ que o autor pensa, o que ele escreve e como utiliza os recursos da escrita para se fazer compreender.

\section{Referências}

DALLA ZEN, Maria Isabel Habckost. Foi num dia ensolarado que tudo aconteceu: práticas culturais em narrativas escolares. 2006. 194f. Tese (Doutorado) - Universidade Federal do Rio Grande do Sul. Faculdade de Educação. Programa de Pós-Graduação em Educação, Porto Alegre, 2006.

FERREIRO, Emilia. Cultura escrita e educação: conversas de Emilia Ferreiro com Jose Antônio Castorina, Daniel Goldin e Rosa Maria Torres. Porto Alegre: ARTMED Editora, 2001. 
GARCIA, Rolando. Criar para compreender: A concepção piagetiana do conhecimento. In: TEBEROSKY, Ana; TOLCHINSKY, Liliana (Org.). Substratum: Temas fundamentais em Psicologia e Educação. Tradução de Beatriz Affonso Neves. Porto Alegre: Artes Médicas, v. 1, n. 1 (Cem anos com Piaget), p. 47-55, 1997.

GERALDI, João Wanderley. Portos de passagem. São Paulo: Martins Fontes, 1997.

GÓES, Maria Cecília Rafael. A criança e a escrita: explorando a dimensão reflexiva do ato de escrever. In: SMOLKA, Ana Luiza; GÓES, Maria Cecília (Orgs.). A linguagem e o outro no espaço escolar: Vygotsky e a construção do conhecimento. Campinas: Papirus, p. 99-117, 1993. Coleção Magistério: Formação e Trabalho Pedagógico.

$\mathrm{KOCH}$, Ingedore Grunfeld Villaça; TRAVAGLIA, Luis Carlos. A coerência textual. São Paulo: Contexto, 1990.

PIAGET, Jean. A construção do real na criança. São Paulo: Ática, 2001.

PIAGET, Jean. A noção de tempo na criança. Rio de Janeiro: Record, s/d.

PIAGET, Jean; INHELDER, Bärbel A origem da idéia de acaso na criança. Rio de Janeiro: Record, s/d.

PIAGET, Jean; INHELDER, Bärbel. Da lógica da criança à lógica do adolescente. São Paulo: Pioneira, 1976.

PIAGET, Jean. A tomada de consciência. São Paulo: Melhoramentos, Ed. da Universidade de São Paulo, 1977.

PINHEIRO, Flávia Isaia. Piaget e as histórias infantis: uma aproximação possível para alfabetizar letrando. 2004. 191f. Dissertação (Mestrado) - Universidade Federal do Rio Grande do Sul. Faculdade de Educação. Programa de Pós-Graduação em Educação, Porto Alegre, 2004.

SMOLKA, Ana Luiza Bustamante; GÓES, Maria Cecília Rafael. A criança e a linguagem escrita: considerações sobre a produção de textos. In: SORIANO DE ALENCAR, Eunice M. S. (Org.). Novas contribuições da psicologia aos processos de ensino e aprendizagem. São Paulo Cortez, p. 51-70, 1992. 


\section{ANEXO I}

\section{$1^{\mathrm{a}}$ tira}

Talita tinha a mania de dar nomes de gente aos objetos da casa, e tinham de ser nomes que rimassem. Assim, por exemplo, a mesa, para Talita, era Dona Teresa, a poltrona era Vó Gordona, o armário era o Doutor Mário. A escada era Dona Ada, a escrivaninha era Tia Sinhazinha, a lavadora era Prima Dora, e assim por diante.

\section{$2^{\mathrm{a}}$ tira}

Os pais de Talita achavam graça e topavam a brincadeira. Então, podiam-se ouvir conversas tipo como esta:

- Filhinha, quer trazer o jornal que está em cima da Tia Sinhazinha?

- É pra já, papai. Espere sentado na Vó Gordona, que eu vou num pé e volto noutro.

Ou então:

- Que amolação, Prima Dora está entupida, não lava nada! Precisa chamar o mecânico.

- Ainda bem que tem roupa limpa dentro do Doutor Mário, né mamãe?

E todos riam.

\section{$3^{\mathrm{a}}$ tira}

Mas uma tarde, Talita estava na sala com a mamãe, assistindo televisão, quando tocou a campainha. Talita correu e foi logo abrindo a porta, sem antes verificar quem era. E não é que eram dois ladrões armados?! Os mal-encarados sujeitos empurraram Talita e foram entrando, de armas apontadas:

- Isto é um assalto! Entregue o dinheiro e as jóias, madame, e nem um pio, está ouvindo?! 


\section{$4^{\mathrm{a}}$ tira}

Talita agarrou-se à mamãe, as duas mudas de susto.

- O cofre, rápido! - repetiu o ladrão, bravo. - Abra o cofre, rápido!

- É pra já, madame. Mexa-se, se não quer que aconteça nada com a menina - ameaçou o outro.

A mamãe - que remédio! - foi logo tirando o quadro que escondia a porta do cofre embutido na parede, e começou a mexer no segredo, nervosa, enquanto Talita olhava, apavorada. Nisso, o telefone tocou. Uma, duas, três vezes.

\section{$5^{\mathrm{a}}$ tira}

- Só faltava isto! - resmungou um dos ladrões.

- Deve ser o papai - murmurou Talita, quase chorando. Ele sempre telefona à tarde para saber da gente...

- Droga! - rosnou o outro. - Se ninguém responder, o homem vai estranhar...

- Então atenda logo - gritou o outro, - A senhora não, madame, cuide do cofre! Você, menina, atenda logo! E cuidado com o que vai dizer! Não deixe perceber nada, senão...

\section{$6^{\mathrm{a}}$ tira}

- Alô! - obedeceu Talita, trêmula, enquanto o ladrão tirava o fone da extensão no vestíbulo, para ouvir a conversa.

- Talita? - era a voz do papai. - Tudo bem aí, filhota?

- Tu... tudo...be...bem...papai... - gaguejou Talita. E o ladrão olhou feio para ela.

- Talita - disse o papai - avise a mamãe que eu vou chegar atrasado para o jantar... mais ou menos uma hora. Você está me ouvindo, filha?

- Es...estou....sim...Vo...você...vai che...chegar...atra... trasado...

- A sua voz está diferente, Talita. Vocês estão bem mesmo?

O ladrão apontou a arma para a menina:

- Vê lá o que fala, e não gagueje! - susurrou ele, ameaçador. 


\section{$7^{\mathrm{a}}$ tira}

Então Talita fez um esforço, firmou a voz e respondeu:

- Tudo bem, papai, eu e a mamãe estamos bem. Só que um pouco preocupadas com o Tio Onofre.

- Tio Onofre? - estranhou o papai.

- Pois é, papai. Telefonaram agora há pouco, dizendo que o Tio Onofre teve uma crise de apendicite aguda e teve de ser operado com urgência. A esta hora já devem estar abrindo a barriga dele...

- É mesmo? - disse o papai, após pequena pausa. - Foi de repente, não é?

\section{$8^{\mathrm{a}}$ tira}

O ladrão, satisfeito com a resposta da menina, fazia sinais para ela terminar a conversa:

- Acabe logo com este papo furado! - sussurrou ele. E Talita apressou-se a obedecer:

- Eu falo pra mamãe que você vai chegar atrasado para o jantar. Até LOGO, papai! - E Talita desligou o telefone.

\section{$9^{\mathrm{a}}$ tira}

- Bem bom! - disse um ladrão para o outro. Agora temos tempo de sobra para fazer o serviço!

- Mesmo assim, quanto mais depressa, melhor. Mexa-se, madame! Vai demorar muito pra abrir este cofre? - rosnou o ladrão.

As mãos da mamãe tremiam muito:

- O senhor me deixa nervosa, com esta arma apontada... assim eu não consigo acertar o segredo...

- Pois não esquente, madame - falou o outro. - Não ouviu que o seu marido vai chegar muito atrasado? Temos tempo que chegue. Gordona:

E, voltando-se para Talita, ordenou, apontando para a Tia 
- E você, menina, senta aí na poltrona e fica bem quietinha, enquanto meu colega e eu revistamos as gavetas da escrivaninha.

\section{$10^{\mathrm{a}}$ tira}

Os minutos passavam. Na sala, só se ouviam as vozes estridentes do desenho animado na televisão, abafando os outros ruídos.

E só Talita, porque estava muito atenta, ouviu o estalinho leve duma chave na fechadura da porta, enquanto a mamãe abria o cofre. E, bem no momento em que os ladrões se precipitavam para ver o conteúdo do cofre, a porta da entrada se abriu de repente, silenciosamente, e dois policiais irromperam na sala, apontando as armas nas costas dos bandidos:

- Polícia! Larguem as armas! Mãos ao alto!

\section{$11^{\mathrm{a}}$ tira}

Atrás dos policiais, entrou correndo o pai de Talita, de braços abertos:

- Graças a Deus, vocês estão bem! - E ele envolveu a mulher e a filha num só grande abraço.

As duas até choraram de emoção e alívio.

E depois que acabou a agitação e os dois policiais levaram os assaltantes presos, a mamãe perguntou ao papai:

- Mas, querido, você não disse que ia chegar atrasado? Como foi que adivinhou o que estava acontecendo e chegou assim, em cima da hora?

\section{$12^{\mathrm{a}}$ tira}

O papai piscou um olho para a Talita.

- E desde quando a nossa filha tem um tio chamado Onofre? Onofre, aqui em casa, só rima com cofre. E se o cofreOnofre estava sendo operado... se estavam "abrindo a barriga dele", bem...

E todos os três caíram na gargalhada. 


\section{$13^{\mathrm{a}}$ tira}

A OPERAÇÃO DO TIO ONOFRE

Uma história policial

Autora: Tatiana Belinky

\section{ANEXO II}

Leia o quadro abaixo para imaginar uma história a partir dele.

\begin{tabular}{|l|l|l|}
\hline \multicolumn{1}{|c|}{ Perguntas } & \multicolumn{1}{|c|}{ Respostas } & \multicolumn{1}{c|}{ Anotações } \\
\hline 1) Com quem acon- & 1) Dona Renata. & 1) Senhora trabalha- \\
2) Perda da casa. & dora, mãe de três fi- \\
teceu a história? & 3) Na segunda-feira & lhos. \\
2) O que aconteceu? & do mês passado. & 2) Casa com pátio, \\
3) Quando aconte- & 4) Na rua em que & dois quartos, cozi- \\
ceu? & norava. banheiro e sala \\
4) Onde aconteceu? & $\ldots$ & de jantar. \\
5) Como aconteceu? & $\ldots$ & 3) Eram 4 horas, \\
6) Por que aconte- & $\ldots$ & uma tarde chuvosa. \\
ceu? & & $\ldots$ \\
7) Como terminou? & & $\ldots$ \\
\hline
\end{tabular}

